\title{
ESTUDO DE USUÁRIOS DA BIBLIOTECA PROFESSOR LYDIO BANDEIRA DE MELLO, DA FACULDADE DE DIREITO, DA UFMG: PARTE QUANTITATIVA
}

\author{
JORDEILSON DE LANA SILVA*
}

\begin{abstract}
RESUMO
O presente estudo objetivou analisar o grau de satisfação dos usuários em relação aos serviços oferecidos pela Biblioteca Professor Lydio Bandeira de Mello. Foi realizada uma pesquisa com a comunidade da Faculdade de Direito da Universidade Federal de Minas Gerais, cuja metodologia baseou-se numa análise quantitativa, composta por uma amostra de 148usuários. Para isso, foi aplicado um questionário, no sentido de conhecer a visão que os usuários possuem em relação aos serviços da Biblioteca. Constatou-se que, de modo geral, os usuários estão satisfeitos com os serviços. Entretanto, sugerem melhorias, especialmente no que se refere à atualização do acervo. Este estudo foi importante, uma vez que, além de constituir-se em um canal de comunicação entre os usuários e a Biblioteca, servirá também como instrumento de apoio à gestão, uma vez que, por meio desse feedback, a instituição poderá avaliar melhor as atividades que desenvolve e, consequentemente, propor novos serviços e/ou otimizar os já existentes.
\end{abstract}

PALAVRAS CHAVE: Estudo de Usuários. Biblioteca Jurídica. Biblioteca Professor Lydio Bandeira de Mello.

STUDY OF USERS FROM THE LIBRARY PROFESSOR LYDIO BANDEIRA DE MELLO LIBRARY, FACULTY OF LAW, UFMG: QUANTITATIVE PART

\begin{abstract}
The present study aimed to analyze the degree of satisfaction of the users in relation to the services offered by the Biblioteca Professor Lydio Bandeira de Mello. A study was conducted with the community of the Faculdade de Direito of Universidade Federal de Minas Gerais, whose methodology was based on a quantitative analysis, composed of a sample of 148 users. For that, a questionnaire was applied, in order to know the vision that the users have in relation to the services of the Library. It has been found that, in general, users are satisfied with the services. However, they suggest improvements,
\end{abstract}

Especialista em Biblioteconomia pela Faculdade Venda Nova do Imigrante. Bibliotecário pela Universidade Federal de Minas Gerais. Coordenador da Biblioteca da Faculdade de Pará de Minas. jordeilsonlana@gmail.com 
especially with regard to updating the acquis. This study was important because, in addition to being a communication channel between the users and the Library, it will also serve as a support tool for management, since, through this feedback, the institution can better evaluate the activities which develops and consequently proposes new services and / or optimize existing ones.

KEY WORDS: Study of Users. Legal Library. Biblioteca Professor Lydio Bandeira de Mello.

\section{INTRODUÇÃO}

As Unidades de Informação (UI), historicamente, privilegiam a manutenção dos sistemas de informação, o desenvolvimento das coleções e a execução impecável da classificação, catalogação e indexação. Isso foi realizado,por várias vezes, sem levar em consideração se este esforço estaria sendo direcionado para as reais necessidades dos seus usuários "para alguns, o usuário aparece apenas no final da cadeia documental, quando solicita um serviço". (GUINCHAT; MENOU, 1994, p. 481).

Neste ponto, a avaliação dos UI,tomando por base a opinião dos seus usuários, é incontestavelmente a forma primordial de verificar os pontos centrais positivos e negativos.Além disso, analisa as ocorrências cuja sua complexidade tem o potencial de moldar as rotinas de trabalho do UI.

Segundo Guinchat e Menou (1994), a principal engrenagem de um sistema de informação é justamente o usuário, pois este sistema tem sua existência baseada na disseminação da informação e comunicação científica. Para os autores, é relevante que a base da orientação e da concepção das unidades e dos sistemas de informação sejam definidos em função de suas características, de suas atitudes, de suas necessidades e de suas demandas". (GUINCHAT; MENOU, 1994, p. 482).

Isso posto, o objetivo geral deste trabalho é conhecer o perfil e verificar o grau de satisfação dos usuários da Biblioteca Professor Lydio Bandeira de Mello. Isso será realizado através da verificação dos pontos que a UI deverá melhorar para atender a comunidade de maneira mais satisfatória.

\section{BIBLIOTECA PROFESSOR LYDIO BANDEIRA DE MELLO}

A pesquisa foi realizada na Biblioteca Professor Lydio Bandeira de Mello (BLBM), tendo como instituição mantenedora a Faculdade de Direito da Universidade Federal de Minas Gerais 
(UFMG). A biblioteca também está integrada ao Sistema de Bibliotecas da UFMG, o qual é composta, atualmente, por 25 bibliotecas. Todas elas são subordinadas administrativamente à Diretoria da Unidade Acadêmica e mantêm sua subordinação técnica à Biblioteca Universitária (BU) da UFMG.

Por se tratar de uma Unidade Acadêmica pertencente a UFMG, os objetivos institucionais da FD acabam ligados aos da própria UFMG. Deste modo, sua missão é:

gerar e difundir conhecimentos científicos, tecnológicos e culturais, destacando-se como Instituição de referência na formação de indivíduos críticos e éticos, dotados de sólida base científica e humanística e comprometidos com intervenções transformadoras na sociedade, visando o desenvolvimento econômico, a diminuição de desigualdades sociais e a redução das assimetrias regionais, bem como o desenvolvimento sustentável. (UFMG, 2013, p. 6).

A BLBM foi fundada em 11 de maio de 1892, na cidade de Ouro Preto, onde seu acervo inicial foi formado de doações de importantes juristas da época. (CORRÊA, 1896; HORTA, 1994). O nome da biblioteca é uma homenagem ao professor Dr. Lydio Machado Bandeira de Mello, jurista natural do estado de Minas Gerais, que, se integrou ao corpo docente da Faculdade de Direito da UFMG.

$\mathrm{Na}$ organização da Faculdade de Direito, a biblioteca é vista como um órgão complementar, onde é subdividida em Chefia, Periódicos, Processamento Técnico e Referência. Já o espaço físico da BLBM é dividido em seis andares, sendo eles: primeiro andar (subsolo), onde ficam localizados os livros para empréstimo e as mesas para estudo. $\mathrm{O}$ andar $\mathrm{P}$, onde ficam localizadas a Portaria, o setor de empréstimo, as revistas Lex, as enciclopédias Saraiva, os últimos números do Diário Oficial da união, a consulta à base de dados local mencionadas, os livros da Coleção reserva, as mesas e as salas para estudo em grupo. No $1^{\circ}$ andar, por sua vez, fica a administração geral da BLBM. O $2^{\circ}$ andar localiza-se a coleção de obras raras, memorial e memória técnica e possui acesso restrito devido ao seu valor histórico para a área do direito. Neste andar, também funciona o laboratório de informática. No $3^{\circ}$ andar fica localizado o setor de periódicos doutrinários e de mesas para estudo. $\mathrm{No}^{\circ} \mathrm{e}$ último andar ficam os periódicos de jurisprudência, coleção das Leis, Diário Oficial, Diário da Justiça entre outros. 


\section{ESTUDO DE USUÁRIOS}

O estudo de Usuários, na visão de Araújo (2010, p. 25), trata-se "[...] de um campo [...] com forte caráter empiricista, voltado para a aplicação de métodos prioritariamente quantitativos na busca de padrões e regularidades do comportamento dos usuários [...]. Araújo (2010) salienta que este campo veio se desenvolvendo através das décadas.

Segundo Baptista e Cunha (2007, p. 170), estas pesquisas tiveram "um papel preponderante durante as décadas de 1960 a 1980" e:

seu uso intensivo teve por objetivo garantir uma maior precisão na análise e interpretação dos resultados, tentando, assim, aumentar a margem de confiabilidade quanto às inferências dos resultados encontrados. (BAPTISTA; CUNHA, 2007, p. 170).

De acordo com Dias e Pires (2004), o estudo de usuários é uma investigação que objetiva identificar e caracterizar os interesses, as necessidades e os hábitos de uso de informação de usuários reais e/ou potenciais de um sistema de informação. Deste modo, segundo Pinheiro (1982, p. 1):

o conhecimento do fluxo de informação científica e técnica, de sua demanda, da satisfação do usuário, dos resultados ou efeitos da informação sobre o conhecimento, do uso, aperfeiçoamento, relações e distribuição de recursos de sistemas de informação e tantos outros aspectos direta ou indiretamente relacionados à informação.

Assim sendo, o usuário é a figura central dos sistemas de informação. Conforme Teruel (2005, p. 23), o estudo de usuários:

constitui um conjunto de investigações cujos resultados permitem planificar e melhorar os sistemas de informação. Em geral, a observação sistemática do usuário oferece uma ferramenta de grande valor para tomar decisões, tanto do ponto de vista da gestão das unidades de informação, como da perspectiva do bibliotecário ou documentalista que dia a dia atende seus pedidos.

Figueiredo (1985, p. 134) relata que:

é imprescindível que os sistemas de informação, que têm seus objetivos básicos [em] atender às necessidades e demandas 
de informação dos seus usuários, realizem estudos de usuários para adequar as suas coleções, serviços e produtos àquelas necessidades e demandas.

Portanto, a interação do usuário com a biblioteca deve ser estudada cautelosamente.

\section{METODOLOGIA}

A pesquisa realizada é do tipo descritiva, com abordagem quantitativa. Ela possui o intuito de traçar o perfil e a satisfação dos usuários da Biblioteca, objetivando oferecer sugestões de ações que possibilitem o aumento do contentamento, além da atração dos usuários potenciais.

A população alvo deste estudo foram os usuários da Biblioteca. A amostragem utilizada foi a não probabilística, para proporcionar a possibilidade de extrair elementos totalmente aleatórios e não específicos. A amostra foi formada por 148 usuários da biblioteca, sendo professores, alunos de graduação e pós-graduação, além do corpo técnico da faculdade.

O instrumento utilizado para a coleta de dados foi o questionário, pois favoreceu a coleta de dados quantitativa e qualitativa. Marconi e Lakatos (1991, p. 201) conceitua o questionário como: "[...] um instrumento de coleta de dados, constituído por uma série ordenada de perguntas, que devem ser respondidas por escrito e sem a presença do entrevistador". Cunha (1982) apresenta algumas vantagens dessa metodologia, tais como: rapidez, baixo custo, atinge uma grande parcela da população, oferece maior grau de liberdade e de tempo.

A aplicação ocorreu durante um período de 17 dias, de duas maneiras distintas: a primeira foi o envio do link com o questionário para todos os usurários via e-mail e disponível na página da faculdade e o segundo foi a utilização dos computadores da Biblioteca, onde foi feita uma explicação e, em alguns casos, um acompanhamento na hora de responder ao questionário. Neste caso, os usuários eram convidados a se dirigir ao computador, sem limite de tempo.

Para os dados quantitativos, os resultados foram dispostos em estatísticas básicas para tabulação. Nestes foram utilizados dois tipos de gráficos: pizza e barras, além da utilização de tabelas. 


\section{RESULTADOS E ANÁLISE}

Conforme o gráfico 1, verifica-se que, ao contrário do que a instituição imagina, a maioria dos usuários são alunos do curso de graduação em Ciência do Estado (34\%).Em segunda colocação estão os alunos da pós-graduação $(32 \%)$ e, somente em terceiro lugar, os alunos de graduação em Direito (20\%). Esta conclusão demonstra um desinteresse desse público em relação à biblioteca, pois se esperava que este grupo alcançasse, pelo menos, $50 \%$ do número de respondentes. Isto posto, é de suma importância que a biblioteca verifique, junto a esse grupo, quais as razões para esse desinteresse.

Todavia, verificou-se um grande interesse dos professores em relação à biblioteca. Isso porque, $11 \%$ responderam ao questionário, uma vez que se esperava apenas $3 \%$ de resposta desta categoria de usuários.

Gráfico 1 - Categorias de usuários

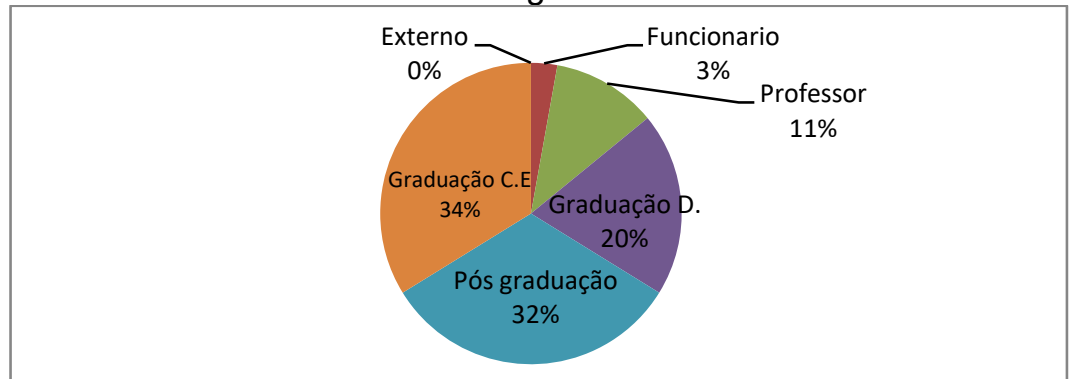

FONTE: Autor

A tabela 1 abaixo demonstra a faixa etária e o gênero da amostragem. Neste momento, é nítido que a amostragem é jovem, pois a maioria está abaixo de 30 anos $(76,1 \%)$, por isso a biblioteca, quando for realizar campanhas, deve-se atentar a este fato, podendo, assim, potencializá-las, atingindo mais de três quartos de seus usuários. Deste modo, otimizará os seus gastos, com pessoal, verba e tempo, podendo destinar este a outra área que esteja defasada. 
Tabela 1 - Faixa etária e gênero

\begin{tabular}{lcc|cc|cc}
\hline \multirow{2}{*}{ Faixa etária } & \multicolumn{2}{c}{$\mathrm{M}$} & \multicolumn{2}{c}{$\mathrm{H}$} & \multicolumn{2}{c}{ Total } \\
Menos de 20 anos & 8 & 5,6 & 8 & 5,6 & 16 & 11,3 \\
Entre 20 e 25 anos & 30 & 21,1 & 22 & 15,5 & 52 & 36,6 \\
Entre 26 e 30 anos & 18 & 12,7 & 22 & 15,5 & 40 & 28,2 \\
Entre 31 e 35 anos & 8 & 5,6 & 4 & 2,8 & 12 & 8,5 \\
Entre 36 e 40 anos & 0 & 0,0 & 4 & 2,8 & 4 & 2,8 \\
Entre 41 e 45 anos & 4 & 2,8 & 2 & 1,4 & 6 & 4,2 \\
Entre 46 e 50 anos & 0 & 0,0 & 4 & 2,8 & 4 & 2,8 \\
Entre 51 e 55 anos & 4 & 2,8 & 2 & 1,4 & 6 & 4,2 \\
Mais de 55 anos & 2 & 1,4 & 0 & 0,0 & 2 & 1,4 \\
Total & 74 & 52,1 & 68 & 47,9 & 142 & 100,0 \\
\hline
\end{tabular}

FONTE: Autor

Outro ponto que a tabela demonstra é que não há uma diferença satisfatória entre gêneros, pois a distinção é de apenas $4,2 \%$. Isto posto, a biblioteca deverá se preocupar igualitariamente com a questões especificas de cada gênero,dando ênfase às questões comuns.

Verificou-se, também, os idiomas que a amostragem tem fluência. $O$ inglês aparece em primeiro lugar, com $76,8 \%$, o espanhol em segundo com 52,1\%. Desta maneira, a biblioteca também poderá incorporar ao seu acervo, seja por compra ou por doação, obras nestes idiomas, uma vez que a sua comunidade tem tal fluência.

Contudo, $17,6 \%$ da amostragem não possui nenhuma fluência em outro idioma, além do português. $57 \%$ tem fluência em mais de dois idiomas, constatando, assim, que a biblioteca poderá investir em obras de outros idiomas, como inglês e espanhol.

A tabela 2 revela que os usuários da biblioteca que a utilizam diariamente (12) vão no turno da tarde, (11) para estudar ou para fazer trabalhos, visto que o tempo que estes permanecem é superior a duas horas.

Tabela 2 - Frequência

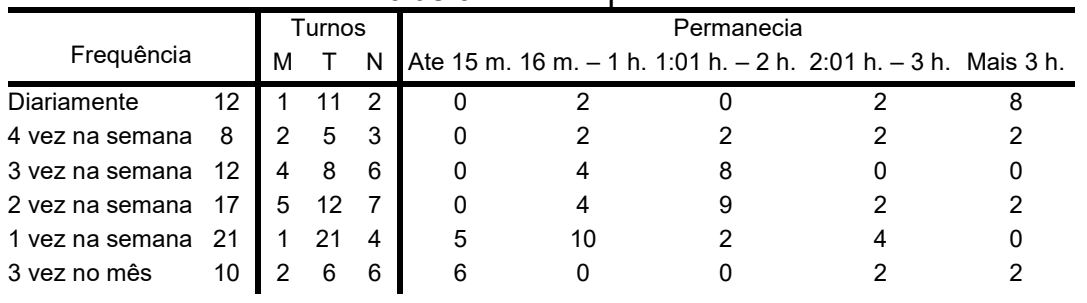


Continuação

\begin{tabular}{|c|c|c|c|c|c|c|c|c|c|}
\hline \multirow{2}{*}{\multicolumn{2}{|c|}{ Frequência }} & \multicolumn{3}{|c|}{ Turnos } & \multicolumn{5}{|c|}{ Permanecia } \\
\hline & & $M$ & $\mathrm{~T}$ & $\mathrm{~N}$ & Ate $15 \mathrm{~m}$ & . - & h. - & h. - & ais $3 \mathrm{~h}$. \\
\hline 2 vez no mês & 12 & 5 & 9 & 4 & 0 & 12 & 0 & 0 & 0 \\
\hline 1 vez no mês & 40 & 10 & 23 & 7 & 12 & 24 & 4 & 0 & 0 \\
\hline Nunca & 10 & - & - & - & - & - & - & - & - \\
\hline Total & 142 & 30 & 95 & 39 & 23 & 58 & 25 & 12 & 14 \\
\hline
\end{tabular}

FONTE: Autor

Os usuários que têm uma frequência de utilização da biblioteca de quatro vezes na semana (8), geralmente utilizam o turno da tarde (5) e da noite (3), para executar as suas atividades em tempos variados. Já os usuários que têm uma rotina de três vezes na semana (12), geralmente utilizam ambos os turnos, contudo vão à biblioteca entre 16 minutos e até duas horas (12), para fazer pesquisas ao acervo. O mesmo ocorre com os usuários que vão a biblioteca 1 ao mês (40).

Quanto aos turnos, é nítido que o turno da tarde (95), é o mais frequentado pelos usuários, seguido do turno da noite (39), e da manhã (30). Desta forma, a concentração de funcionários deve ser massiva no turno da tarde, para suprir as necessidades da comunidade.

Outro ponto a ser mencionado é o fato de 10 usuários sinalizarem que não frequentaram a biblioteca, expondo seus motivos em outra pergunta do questionário. Dito isso, os motivos principais destes usuários foram "acervo desatualizado, sala de estudos desconfortável, dificuldade de encontrar obras nas estantes". Ambas as respostas apareceram em, pelo menos, 5 respostas distintas, configurando-se, assim, alguns dos principais dificultadores para estes usuários.

No gráfico 3, estão expostos os principais interesses dos respondentes em utilizar a biblioteca. Como já era esperado, o empréstimo domiciliar ficou em primeiro lugar, com $97 \%$ dos respondentes, seguido pela realização de pesquisas para produzir artigos $(47,7 \%)$, e, posteriormente, pesquisas para realização de dissertação e tese $(43,2 \%)$, leitura $(39,4 \%)$ e, assim, sucessivamente. O surpreendente foi que um professor colocou que um dos principais interesses em utilizar a biblioteca é o preparo de aulas $(0,8 \%)$, onde se demonstra o potencial da biblioteca em oferecer informações. 
Gráfico 3 - Interesses

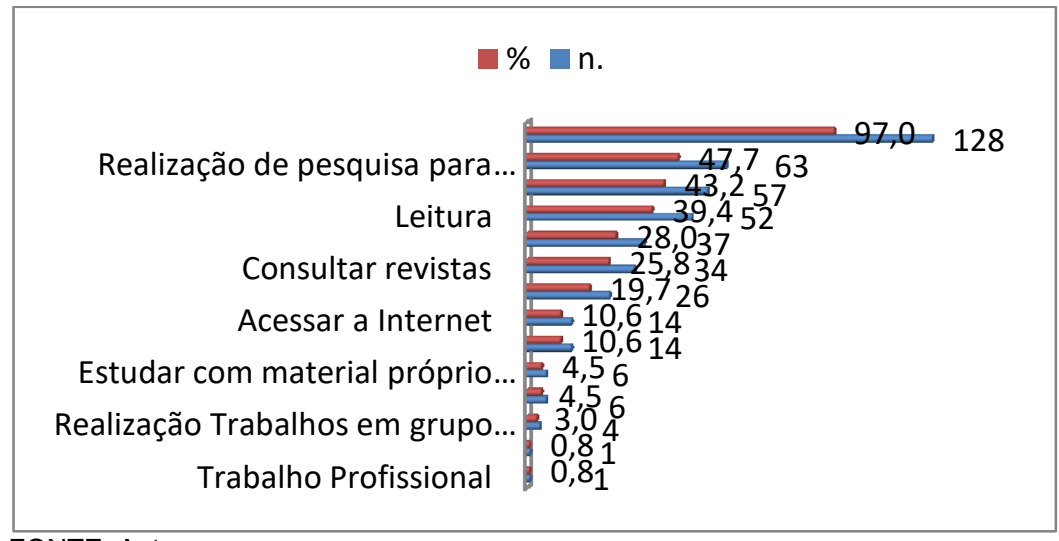

FONTE: Autor

Já o gráfico 4 nos revela os documentos que os respondentes têm mais interesse. Como já era esperado, os livros $(98,5 \%)$ seriam o primeiro lugar, contudo foi surpreendente que as dissertações e teses $(43,2)$ tenham uma procura maior que os periódicos científicos impressos (32,6\%), e os periódicos do Portal Capes (8,3\%).

Outro dado importante é que nenhum dos usuários demonstrou interesse pelos CDs e DVDs (0,0\%). Além disso, os jornais diários $(2,3 \%)$ e revistas semanais $(3,8 \%)$ também não tiverem uma procura satisfatória. Deste modo, em ambos os casos deverão ser investigadas se tais assinaturas dos periódicos estão atendendo às expectativas dos usuários.

Gráfico 4 - Documentos

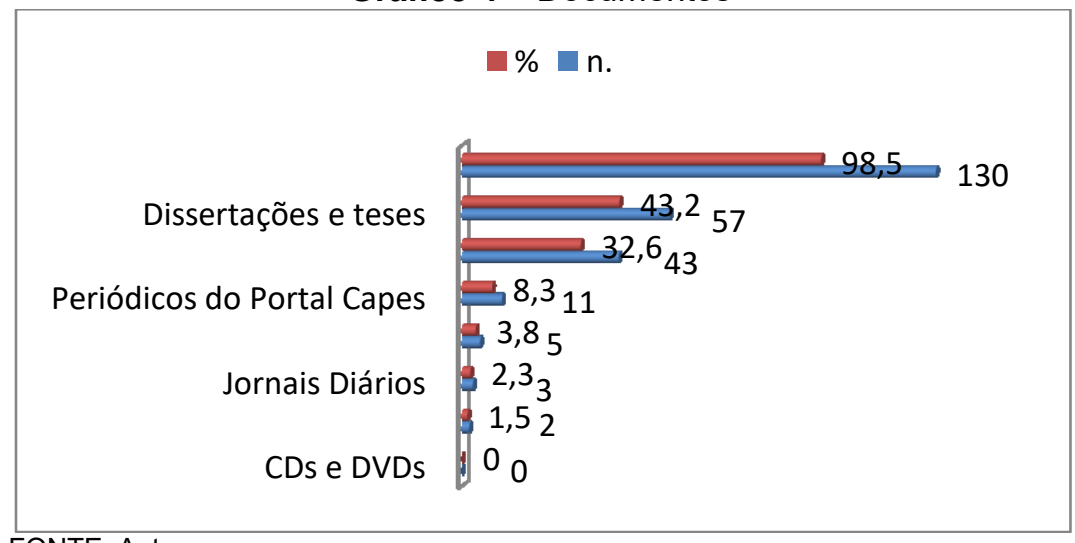

FONTE: Autor 
As fontes de informação, disponíveis na biblioteca, que os usuários mais utilizam, são: a internet $(53,8 \%)$ ficou em primeiro lugar, os manuais $(40,9 \%)$ em segundo lugar e os livros da coleção reserva $(34,1 \%)$ em terceiro lugar. Isso demonstra que esta coleção ainda tem uma parcela dos usuários que a utilizam.

Os documentos da referência como os dicionários $(9,1 \%)$, ficaram com uma procura baixa, e as enciclopédias, bibliografias e biografias não foram mencionadas. Desta forma, deve-se rever esta coleção, principalmente com relação à quantidade de itens.

O gráfico 6 retrata a frequência com que os usuários obtêm as informações que desejam na biblioteca.Nela, $49 \%$ dos respondentes, quase sempre,obtêm a informação que deseja, seguido de sempre (25\%). Desta forma, os usuários, quando vão à biblioteca com interesse em uma determinada informação, saem satisfeitos, na grande maioria das vezes, uma vez que nunca $(0,0 \%)$ ou raramente $(5 \%)$ ficam desinformados. Isso demonstra que a capacidade da biblioteca em fornecer a informação que seus usuários necessitam tem sido eficaz.

Gráfico 6 - Informação que desejada

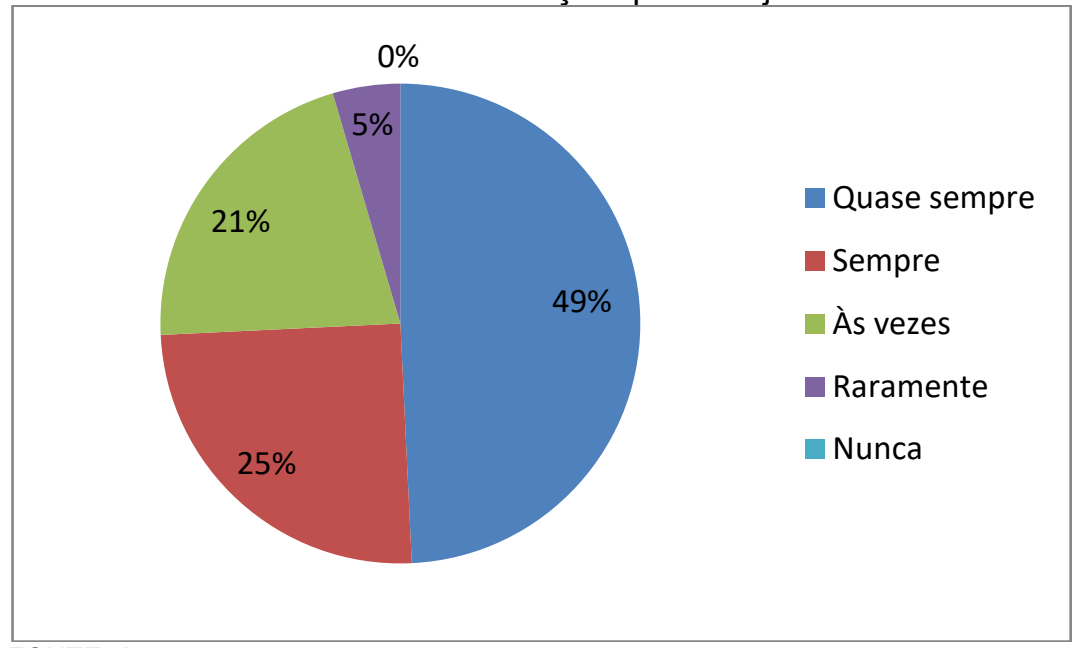

FONTE: Autor

Segundo o gráfico 7 , os documentos em geral que os usuários procuram na biblioteca estão disponíveis (62\%), demonstrando, assim, que o tempo de empréstimo e a quantidade de exemplares, aparentemente, é satisfatória. 
Gráfico 7 - Disponibilidade dos documentos

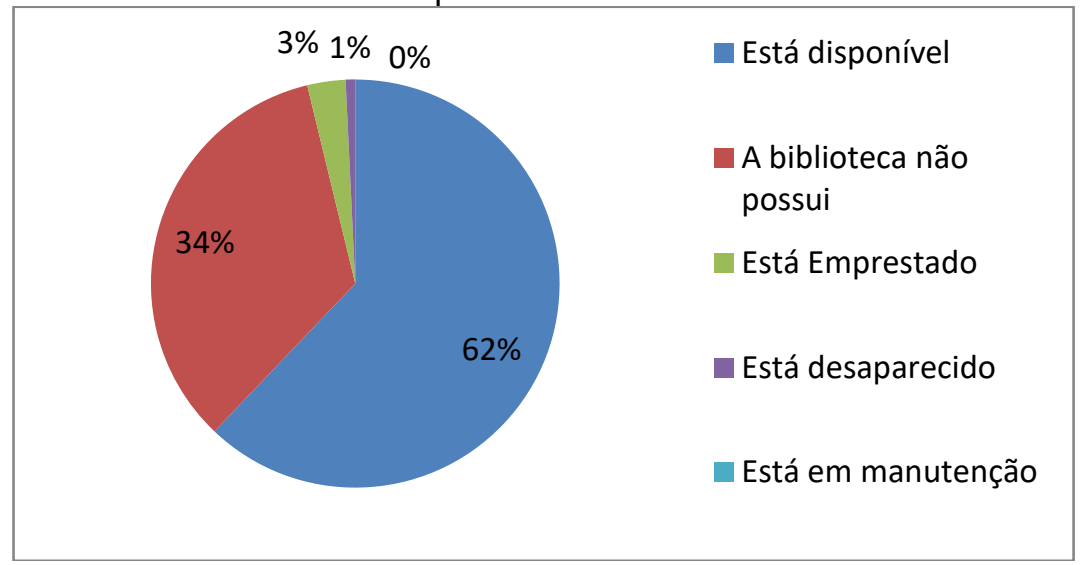

FONTE: Autor

Contudo, uma parcela considerável de $34 \%$ dos respondentes colocaram que os documentos que eles procuram, geralmente a biblioteca não possui. Deste modo, a biblioteca precisa empenhar-se em consegui-los para atender a esta demanda.

O gráfico 8 revela que a atividade dos usuários, quando estes não encontram os documentos desejados. $45 \%$ destes pedem ajuda ao bibliotecário de referência da instituição, demonstrando, assim, a importância deste profissional e setor para a biblioteca.

Gráfico 8 - Atividade dos usuários

\begin{tabular}{|l|l|}
\hline $18 \%$ & $\begin{array}{l}\text { Pede ajuda ao bibliotecário } \\
\text { de referência } \\
\text { arocura em outra Biblioteca }\end{array}$ \\
$45 \%$ & $\begin{array}{l}\text { Procura outro que possa } \\
\text { substituí-lo } \\
\text { Compra o documento }\end{array}$ \\
$29 \%$ & Desiste do documento \\
Outros
\end{tabular}

FONTE: Autor 
Outro ponto que o gráfico 8 demonstra é a independência dos usuários da biblioteca. $29 \%$ deles procura o documento desejado em outra biblioteca, e $18 \%$ procura outro documento para substituí-lo.

Apenas $4 \%$ dos respondentes colocaram que, quando não encontram o documento, compram-no. Apenas 2\% desistem deste documento.

O gráfico 9 nos revela como os usuários desejam obter informações sobre os produtos e serviços. Neste, o e-mail $(91,7 \%)$ foram os mecanismos de disseminação de informação preferido pelos respondentes. Seguido de redes sociais $(42,4 \%)$, web sites $(32,6 \%)$, cartazes $(26,5 \%)$ e, por fim, das mensagens de texto $(6,8 \%)$. Demonstrando, assim, que os mecanismos de divulgação de informação estão adequados, uma vez que o e-mail e os websites são massivamente utilizados pela biblioteca.

Contudo, poderia implantar outros mecanismos de divulgação, como uma rede social, visto que a maior parte da faixa etária dos respondentes está abaixo de 30 anos. Desta forma, a biblioteca poderá potencializar a divulgação de seus produtos e serviços.

Gráfico 9 - Mecanismos de Comunicação

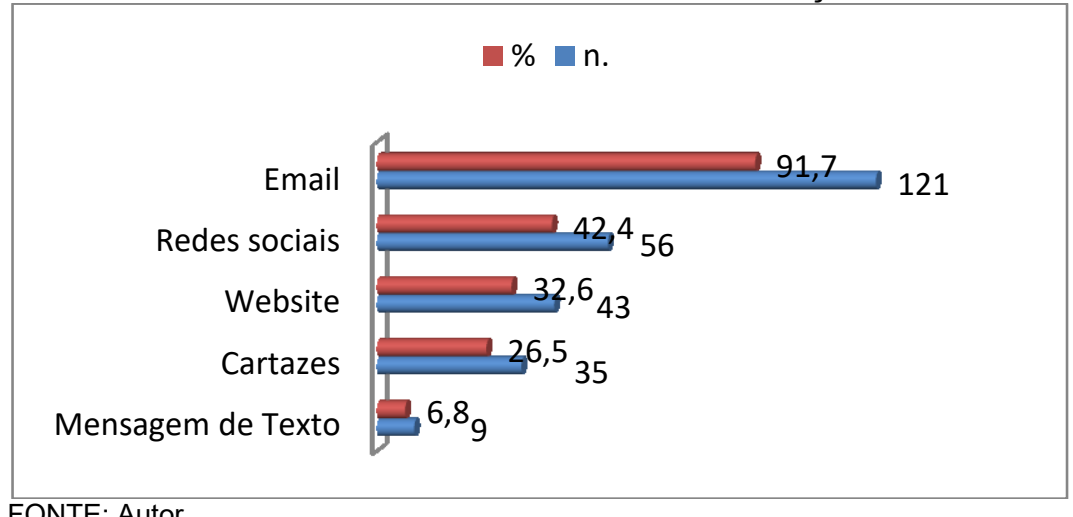

FONTE: Autor

Os serviços mais utilizados pelos usuários são os prestados de forma online, que ficaram em primeiro (renovação 86,6\%) e segundo lugar (reserva 54,9\%). 
Gráfico 10 - Serviços

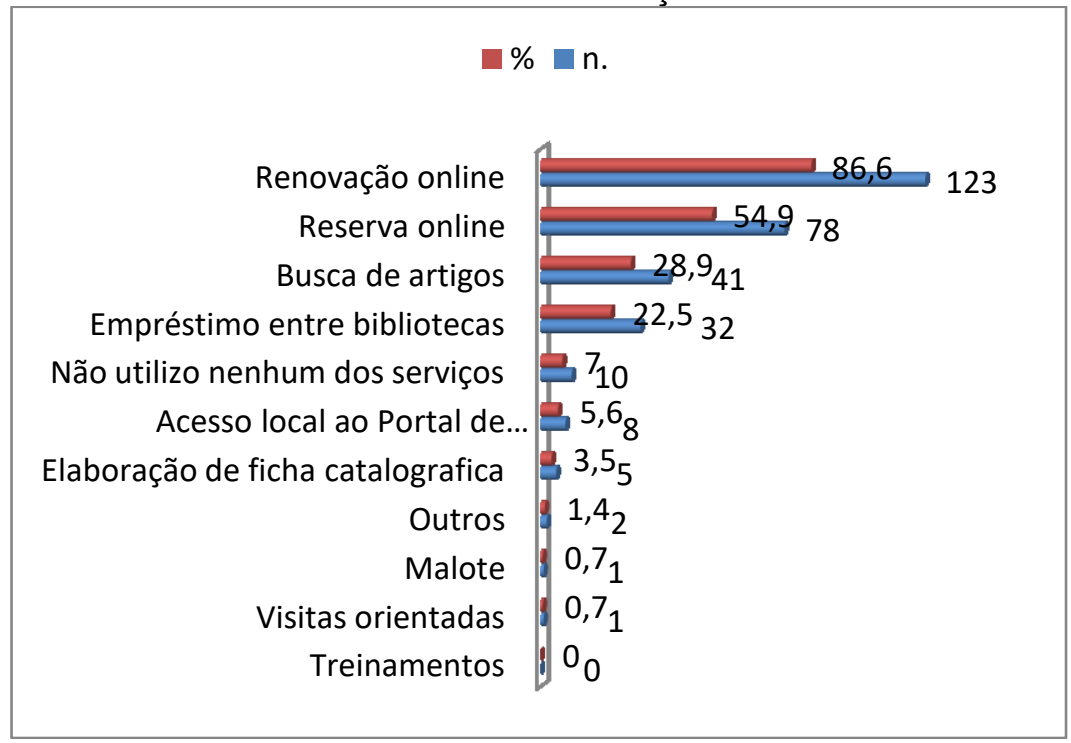

FONTE: Autor

\section{CONCLUSÃO}

Conclui-se que a Biblioteca deverá atentar-se para as melhorias, de maneira a buscar, constantemente, a solução para possíveis carências e, junto à entidade superior, captar recursos, quando necessários à geração de mudanças e desenvolvimento de determinadas atividades. Esses respaldos devem focalizar, principalmente, no acervo desatualizado, nas salas de estudos desconfortáveis, na dificuldade de encontrar obras nas estantes e na sinalização da biblioteca no geral.

Sugere-se, portanto, que a biblioteca, realize, futuramente, novas pesquisas direcionadas a usuários, pois bibliotecas jurídicas, assim como outras modalidades de bibliotecas, possuem públicos e necessidades voláteis, estando em constantes mudanças e requerendo novas alternativas, que satisfaçam, eficientemente, o desejo e a busca por informações.

Ademais, é imprescindível a realização de treinamento de usuários pela Biblioteca. Isso porque esta opção irá sanar as dificuldades de seus usuários com relação à pesquisa e à localização dos documentos desejados. 


\section{REFERÊNCIAS}

ARAÚJO, C. A. Á. Estudos de usuários conforme o paradigma social da ciência da informação: desafios teóricos e práticos de pesquisa. Informação \& Informação, Londrina, v. 15, n. 2, p. 23-39, jul./dez. 2010.

CORRÊA, Raymundo. Memória histórica da faculdade livre de direito de minas gerais. Revista da faculdade de direito da UFMG, v. 1, n. 2 p. 139-177, 1896.

BAPTISTA, S. G.; CUNHA, M. B. da. Estudo de usuários: visão global dos métodos de coleta de dados. Perspectivas em Ciência da Informação, Belo Horizonte, v. 12, n. 2, p. 168-184, maio/ago. 2007.

CUNHA, Murilo Bastos da. Metodologias para estudo dos usuários de informação científica e tecnológica. Revista de Biblioteconomia de Brasília, Brasília DF, v. 10, n. 2, p. 5-19, jul./dez. 1982.

DIAS, Maria Matilde Kronka e PIRES, Daniela. Usos e usuários da informação. São Carlos: EdUFSCar, 2004. 48p.

FIGUEIREDO, Nice Menezes de. Estudos de usuários como suporte planejamento e avaliação de informação. Ci, Inf., Brasília, v. 14, n. 2, p. 127-135, jul./dez. 1985.

GUINCHAT, C.; MENOU, M. Introdução geral às ciências e técnicas da informação e documentação. Brasília: IBICT, 1994. Disponível em: <http://livroaberto.ibict.br/handle/1/1007>. Acesso em: 02 jul. 2018.

HORTA, Raul Machado. A Faculdade de Direito da Universidade Federal de Minas Gerais no Centenário de sua Fundação. Revista da Faculdade de Direito da UFMG, Belo Horizonte, v. 34, n. 34, p. 15-46, 1994.

MARCONI, Marina de Andrade; LAKATOS, Eva Maria. Fundamentos de metodologia científica. 8. ed. São Paulo: Atlas, 2017. 346p

PINHEIRO, Lena Vânia Ribeiro. Usuário - Informação: o contexto da ciência e da tecnologia. Rio de Janeiro: Livros Técnicos e Científicos Editora, 1982. 66p.

TERUEL, Aurora González. Los estudios de necesidades y usos de la información: fundamentos y perspectivas actuales. Gijón: Ediciones Trea, 2005. 181p.

UFMG. UNIVERSIDADE FEDERAL DE MINAS GERAIS. Plano de desenvolvimento institucional: 2013 - 2017. [Belo Horizonte], 2013. Disponível em: <https://www.ufmg.br/conheca/pdi_ufmg.pdf>. Acesso em: 19 jun. 2018.

Recebido em: 28/08/2018

Aceito em: 20/04/2019 